\title{
NOTES ON GOODYERA LANCEOLATA (ORCHIDACEAE), A MYSTERIOUS ORCHID SPECIES
}

\author{
Sahut Chantanaorrapint ${ }^{1}$, Tidarat Puangpairote, Jarearnsak Sae Wai \\ \& AMONRAT CHANTANAORRAPINT
}

\begin{abstract}
Goodyera lanceolata Ridl., a rare orchid species previously known only from Selangor, Peninsular Malaysia, was newly discovered in lower montane forests in southern Thailand. A description, line drawings and photographs are provided, and its diagnostic characters and geographical distribution are briefly discussed.
\end{abstract}

Key words: Goodyera lanceolata, distribution, new record, orchid, peninsular Thailand, rare species

Sahut Chantanaorrapint, Tidarat Puangpairote \& Jarearnsak Sae Wai, Department of Biology, Faculty of Science, Prince of Songkla University, Hat Yai, Songkhla, 90112, Thailand; e-mail: chantanaorrapint@gmail.com

Amonrat Chantanaorrapint, Faculty of Natural Resources, Prince of Songkla University, Hat Yai, Songkhla 90112, Thailand; e-mail: amonrat.b@psu.ac.th

\section{INTRODUCTION}

Goodyera R.Br. is a genus of terrestrial orchids with about 100 species, widely distributed from North and Central America and Eurasia to northern Queensland and the western Pacific islands and across the Indian Ocean to Madagascar and Mozambique (Pridgeon et al. 2003; Pedersen 2011). The genus is very similar to Hylophila Lindl. in general appearance, but the later differs in the hypochile forming a subglobose sac (Pridgeon et al. 2003).

Eight species have been recorded from Thailand (Seidenfaden 1978; Pedersen 2011). During fieldwork devoted to revising the orchid flora of Thailand, two interesting collections of the genus Goodyera were made in the southern part of the country. Based on the literature and comparisons of herbarium specimens, the unknown collection was identified as Goodyera lanceolata Ridl., which was first established by Ridley (1903) based on a collection from Selangor, Malaysia. Goodyera lanceolata is one of the most mysterious orchids, not only because it was considered endemic to

\footnotetext{
1 Corresponding author
}

Peninsular Malaysia, but also for the remarkable fact that only one sample was previously collected (Ridley 1903; Holttum 1953; Seidenfaden \& Wood 1992). The description and illustration below are based on the recent collections in Thailand.

\section{DESCRIPTION}

Goodyera lanceolata Ridl.

Figs $1 \& 2$

J. Straits Branch Roy. Asiat. Soc. 39: 86. 1903.

TyPe: MALAYSIA. Selangor, Gap, May 1902, Curtis s.n. (HOLOTYPE K000942759, photo seen).

Terrestrial orchid, rhizomatous herb; creeping stem-like rhizome rooting from its nodes, succulent, reddish brown, glabrous. Flowering shoots 20-30 cm tall, erect, reddish; lower part of stem $3.5-5.2 \mathrm{~mm}$ in diameter. Foliage leaves $3-5$, pale to dark green; lanceolate to elliptic, $4.2-6.4 \mathrm{~cm}$ long, $1.3-2.3 \mathrm{~cm}$ wide, acute to acuminate; petiole (including sheaths) $2.3-3.0 \mathrm{~cm}$ long. Inflorescence pubescent, terminal; rachis green, 9-15 cm long, 1.5-3.0 $\mathrm{mm}$ in diameter, 3-12-flowered; bracts pubescent, lanceolate to triangular-ovate, 9-11 $\times$ 3.2-4.3 mm, acuminate. Flowers greenish brown, 

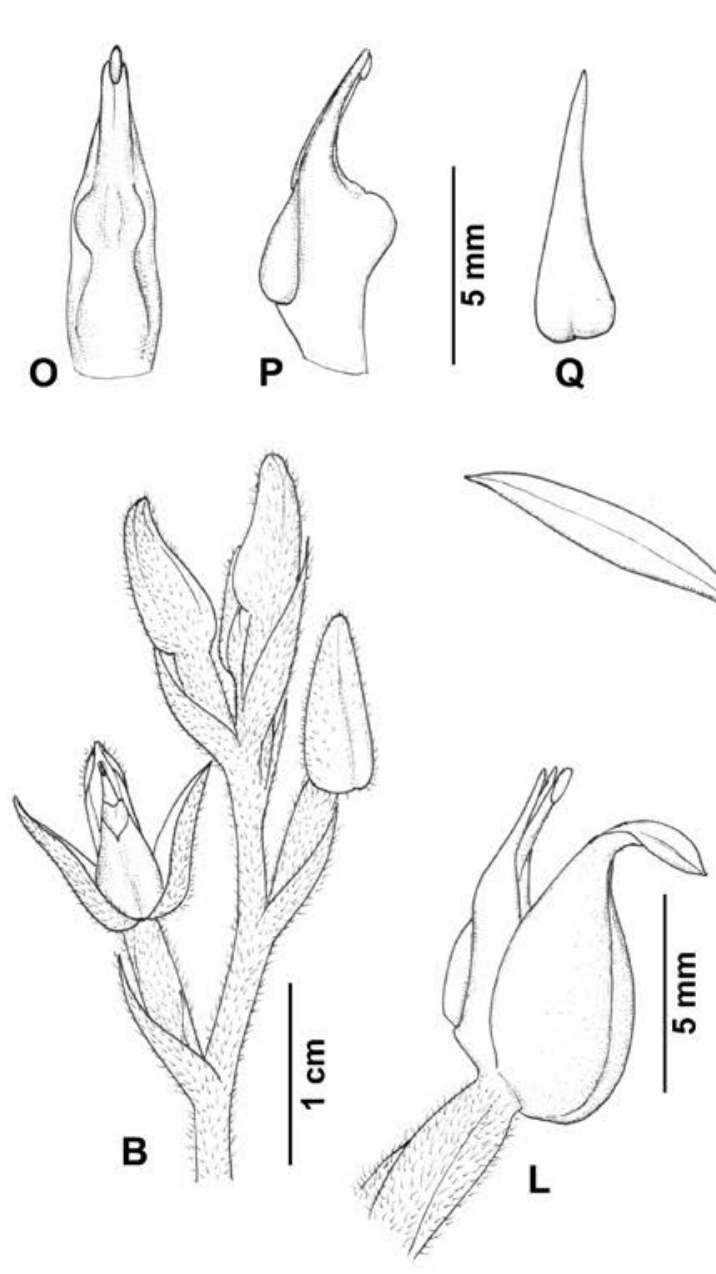

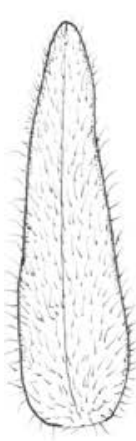

$\mathbf{F}$

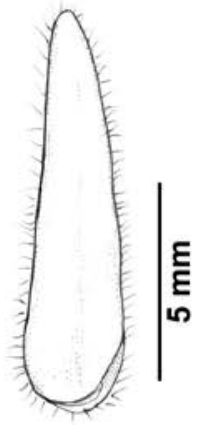

G

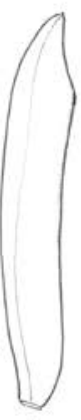

$\mathbf{J}$

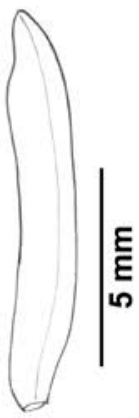

K
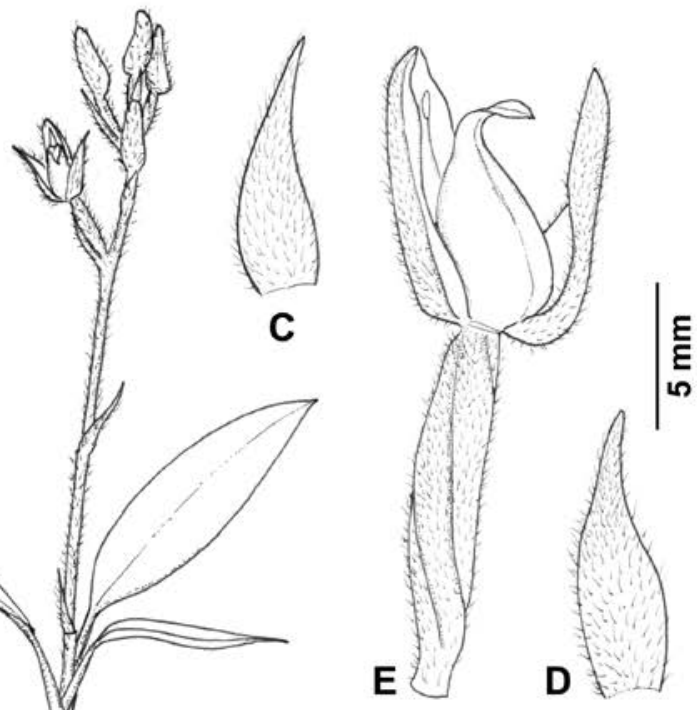

A
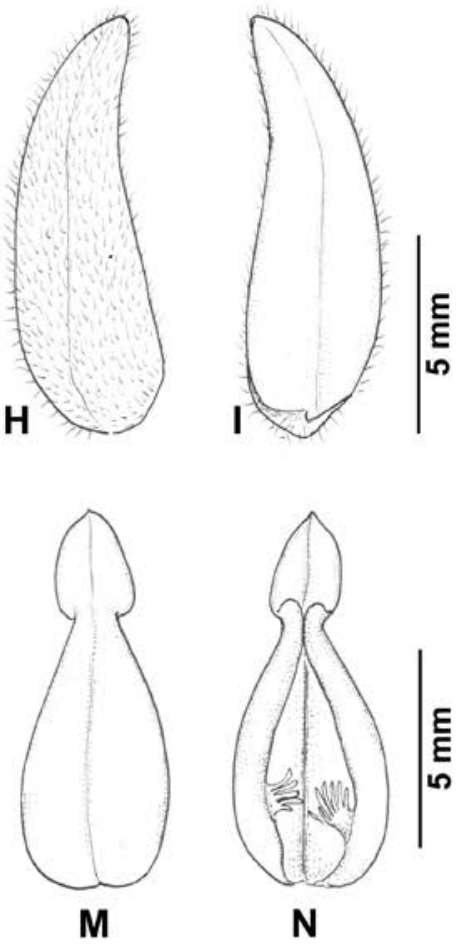

Fig. 1. Goodyera lanceolata Ridl. A - habit, B - inflorescence, C \& D - floral bracts, E - flowers in side view (lateral sepal removed), F \& G - dorsal sepal, H \& I - lateral sepals, J \& K - petals, L - column and labellum in side view, M \& N - labellum, $\mathrm{O} \& \mathrm{P}-$ column, Q - anther cap. Drawn by S. Chantanaorrapint from S. Chantanaorrapint, A. Chantanaorrapint \& J. Wai 03 (PSU). 

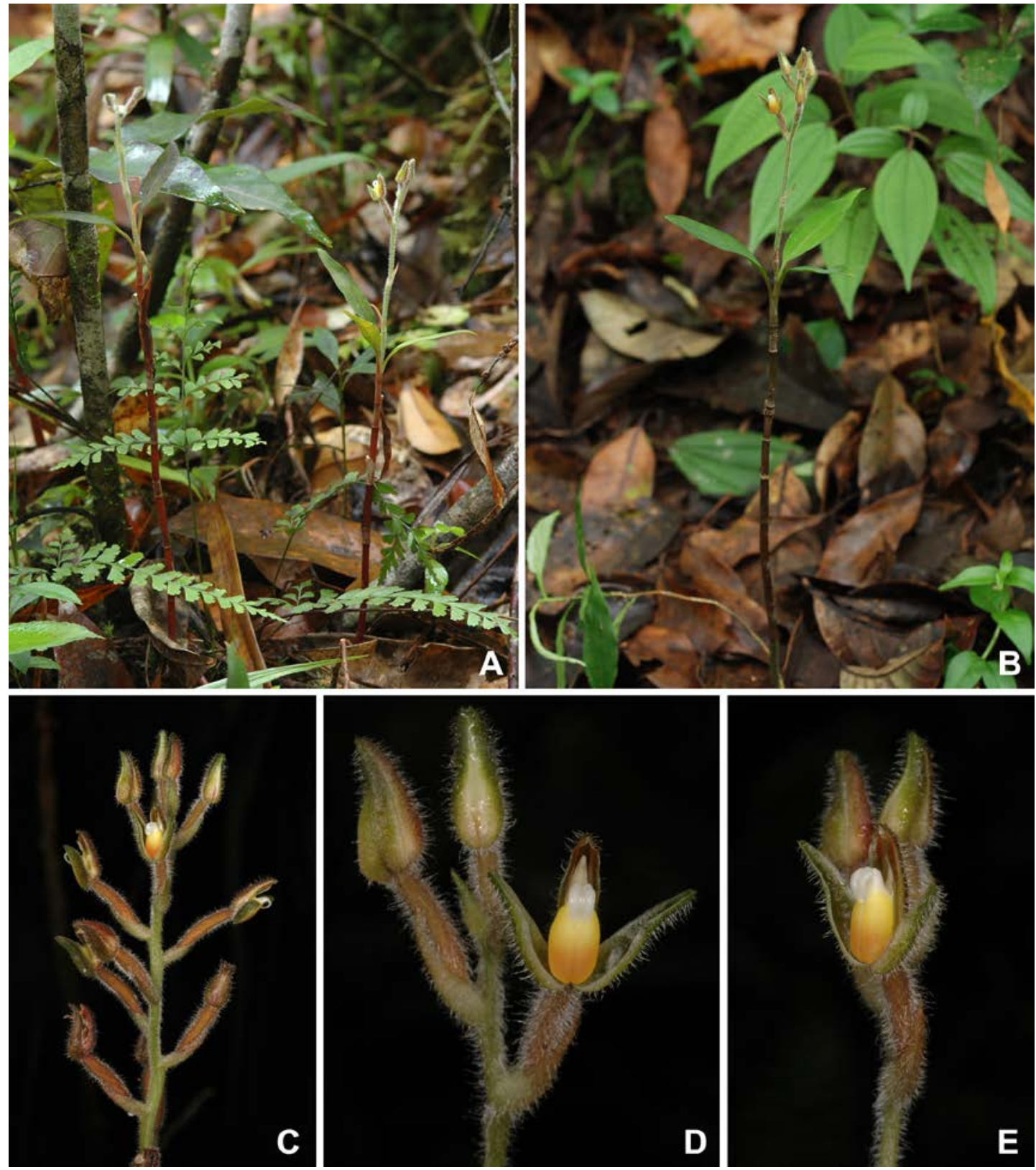

Fig. 2. Goodyera lanceolata Ridl. A \& B - plants in natural habitat, on humus under shade in lower montane forest, C - part of inflorescence, D \& E - flowers. Photo S. Chantanaorrapint.

opening widely. Sepals greenish brown, pubescent on dorsal side; dorsal sepal curved, hood-like, narrowly lanceolate, $11-12 \times 3.0-3.5 \mathrm{~mm}$, obtuse; lateral sepal spreading, obliquely falcate, 11.0-12.5 $\times 3.6-4.2 \mathrm{~mm}$, acute to obtuse. Petals glabrous, forming a hood with the dorsal sepal, slightly falcate, linear, 1-veined, ca $10 \times 1.5 \mathrm{~mm}$, acute. Labellum fleshy, white at apex, yellowish below, narrowly ovate to lanceolate, 9-11 mm long, concave to saccate at base, nearly flat at apex; sac 
shallowly bilobed, with tuft of bristles each side of middle within; apex acute, recurved to reflexed. Column straight, 4.5-5.0 mm long; stigma bilobed; rostellum $3.0-3.5 \mathrm{~mm}$, shortly bifid; anther lanceolate, 6.5-7.0 mm long, ca $2 \mathrm{~mm}$ wide, acuminate; pollinia 2, basitonous; stipe $c a 4 \mathrm{~mm}$ long; viscidium elliptic, $c a 1 \mathrm{~mm}$ long. Ovary reddish brown, pubescent, 10-13 mm long, 1.5-1.8 mm in diameter. Capsule sessile, reddish brown, pubescent, fusiform, 15-20 mm long, 2.0-2.5 mm in diameter. Seed not seen.

Specimens eXamined: THAILAND. NaKhon Si Thammarat province, Khao Nan National Park, ca $1200 \mathrm{~m}$ altitude, 10 May 2007, Khunwasi et al. (BCU); Summit of Khao Ramrome Mt., $08^{\circ} 14^{\prime} 19.75^{\prime \prime} \mathrm{N}$, 99 48'20.23"E, ca $950 \mathrm{~m}$ altitude, 13 May 2007, $S$. Chantanaorrapint, A. Chantanaorrapint \& J. Wai 03 (PSU).

Distribution. Peninsular Malaysia (Selangor) and peninsular Thailand.

Habitat AND ECOLOGY. In Thailand, Goodyera lanceolata was found growing on humus under shade in lower montane forests, between 950 and $1200 \mathrm{~m}$ a.s.l. Flowering and fruiting in May.

TAXONOMIC NOTES. Goodyera lanceolata is characterized by its $(i)$ lanceolate to narrowly elliptic leaves, (ii) hairy flowers, (iii) saccate labellum with a pair of tufts of bristles inside and (iv) very long acuminate anther. Goodyera lanceolata can be confused with $G$. viridiflora (Blume) Blume, a widely distributed species, in flower form and anther shape, but $G$. viridiflora differs from $G$. lanceolata in having cordate-ovate to ovate-elliptic leaf laminas, glabrous flowers, and obliquely oblanceolate to spathulate-rhombic petals.
Goodyera lanceolata was previously known from the type collection only, so this rediscovery after 100 years in Thailand is significant. This is the first record of the species for Thailand and the second report worldwide. The new record represents the northernmost locality of this species. In Thailand it is known only from Nakhon Si Thammarat Province but it may have a wider distribution and may occur in other areas of southern Thailand as well.

ACKNOWLEDGEMENTS. We thank the curators and staff of BCU and BKF for kindly allowing us to study specimens, and Dr. Hubert Kurzweil (SING) and the anonymous reviewer for their valuable comments on the manuscript. This work was supported by the Prince of Songkla University Research Fund under the Plant Genetic Conservation Project under the Royal initiative of Her Royal Highness Princess Maha Chakri Sirindhorn.

\section{REFERENCES}

Holtum R. E. 1953. A Revised Flora of Malaya. 1: Orchids of Malaya. Government Printing Office, Singapore.

Pedersen H. Æ. 2011. Goodyera. In: T. SAntisuK \& K. Larsen, Flora of Thailand. 12(1): 67-79. The Forest Herbarium, Department of National Parks, Wildlife and Plant Conservation, Bangkok, Thailand.

Pridgeon A. M., Cribb P. J., Chase M. W. \& Rasmussen F. N. 2003. Genera Orchidacearum. 2: Orchidoideae (Part 1). Oxford University Press, Oxford.

RIDley H. N. 1903. New Malay Orchids. J. Straits Branch Roy. Asiat. Soc. 39: 71-87.

SeIdenfaden G. 1978. Orchid genera in Thailand VI. Neottioideae Lindl. Dansk Bot. Ark. 32: 1-195.

Seidenfaden G. \& Wood J. J. 1992. The Orchids of Peninsular Malaysia and Singapore. Olsen \& Olsen, Fredensborg. 